Bol. Acad. peru. leng. 55. 2013 (241-261)

\title{
EL CORRECTOR DE TEXTOS: VALOR DE UNA PROFESIÓN
}

\author{
Alicia María Zorrilla \\ Academia Argentina de Letras \\ Universidad del Salvador \\ Fundación LITTERAE
}

Fecha de recepción:

$28 / 02 / 2013$

Fecha de aceptación:

$02 / 04 / 2013$

Estábamos gozando del primer tomo de una edición del Quijote de 1740 cuando hallamos, al comienzo, un párrafo en que Julián del Cerro, escribano del rey, le daba licencia a Juan de San Martín, mercader de libros en esa Corte, para que por una vez pudiera reimprimir y vender, en dos tomos, la historia de don Quijote de la Mancha. Esa reimpresión debía hacerse sobre la base del original, y, con la Certificación del Corrector — ambas palabras con mayúscula-, podría tasarse el precio a que se vendería.

iEn qué gran miramiento se tenía al "Corrector General por su Majestad"! Sin que él revisara la obra, no podía determinarse su precio de venta. Una certificación es un documento en que se asegura la verdad de un hecho. Y, en este, el corrector señalaba que había encontrado en la reimpresión las mismas erratas que contenía el original y, por supuesto, las había subsanado. 
El corrector de textos, verdadero puente entre el autor y el lector, debe volver a ocupar ese lugar en nuestra sociedad y transformar su tarea en una profesión de jerarquía, respetable y respetada. Podrá lograrlo con una formación óptima. Deberá estudiar siempre, brillar por sus conocimientos. Demostrar su competencia tiene que ser preocupación de todos los días para que, en cada empresa donde trabaje, lo sientan necesario, casi imprescindible, y lo consulten constantemente. Esta labor, como otras, exige consagración, un amor entrañable por las palabras, que no son cosas, sino seres que viven con nosotros, por nosotros y que nos ayudan a ser personas.

El corrector puede asemejarse a un pastor, pero de palabras, pues las cuida en lo material (significante, existencia) y en lo espiritual (significado, esencia), es decir, en cuerpo y alma. No puede perderse ninguna en el misterioso horizonte de la página. Todas están bajo su mirada vigilante, que trasciende lo que llamamos realidad para crear su espacio propio y permitirle a él mismo metamorfosearse en vocablos. Durante su labor, este metafórico pastor renuncia inconscientemente a su humanidad terrena y adopta la delicada humanidad de los vocablos, que tienen su cielo. En ese instante diferente, los ojos semejan flechas verbales que buscan varios blancos. Los ojos del corrector oyen, piensan y hablan, y su mirada inquisidora recorre silenciosa las líneas de la escritura como caminos sin destino que desanda y vuelve a recorrer. Es un ser de silencios. Tal vez, ningún verdadero corrector se ha dado cuenta aún de esa fusión sublime que permite parir al hombre-palabra.

Corregir es, sin duda, un arte al que hay que entregarse con pasión, pero también con paciencia y tenacidad. Cuando decimos esto en nuestras clases, no falta quien pregunte qué es la pasión. Desde el punto de vista etimológico, esta voz denota 'sufrimiento'. Y así lo demuestra un poemita de Lope de Vega referido al nacimiento de Jesús: "No lloréis, mi vida, / que me dais pasión, / le dice la Niña / que al Niño parió. / Témplanse los aires / a su dulce voz; / cántale su Madre / y él llora de amor".

Cuando nos referimos al camino profesional elegido por un auténtico llamado interior, podríamos decir que "pasión" por lo que 
hacemos es un sentimiento fuerte que ocasiona un estado de zozobra placentero sin el que no podríamos vivir, un llorar de amor, como dice el poema. No es una paradoja. No significa complacencia ante las dificultades que presentan los trabajos. No implica alegría por padecer. Es un impulso que motiva fervorosamente cada uno de nuestros actos y que se genera, sin duda, por esa relación de belleza entre hombre y palabra, de la que hablamos. Ese sufrimiento, ese amor que duele, reside en querer trabajar muy bien, cada vez mejor, pero con prudencia y sensatez para no transgredir con rigor maniático la escritura ajena. La perfección nunca se alcanza; lo bueno es saber pulir el texto con pericia, con mesura, sin extralimitarse, para soñar con la certeza de haberla conseguido. Hemos encontrado un cuentito del escritor andaluz Juan Ramón Jiménez que bien puede servir como metáfora del corrector obsesivo, es decir, del que, como tantos, por ese afán de ser perfecto, después de leer y releer el texto no ve una errata desgarradora que lo condena. Se titula "El recto"1:

Tenía la heroica manía bella de lo derecho, lo recto, lo cuadrado.

Se pasaba el día poniendo bien, en exacta correspondencia de líneas, cuadros, muebles, alfombras, puertas, biombos. Su vida era un sufrimiento acerbo y una espantosa pérdida. Iba detrás de familiares y criados, ordenando paciente e impaciente lo desordenado. Comprendía bien el cuento del que se sacó una muela sana de la derecha porque tuvo que sacarse una dañada de la izquierda. Cuando se estaba muriendo, suplicaba a todos con voz débil que le pusieran exacta la cama en relación con la cómoda, el armario, los cuadros, las cajas de las medicinas. Y cuando murió y lo enterraron, el enterrador le dejó torcida la caja en la tumba para siempre.

El corrector debe ser "médico" de las palabras — no curandero ni matasanos - para curarlas cuando llegan enfermas por impericia del autor; y, al mismo tiempo, "abogado" para aplicar muy bien las leyes que rigen su uso correcto y aplicarlas como corresponde. El vocablo "médico" deriva del latín medicus, y esta voz, de mederi, verbo que denota "curar, aliviar, cuidar'; "abogado" proviene del verbo latino advocare, 'llamar en

$1<$ http://talent.paperblog.com/el-recto-juan-ramon-jimenez-185752/> [Consulta: 24 de diciembre de 2012].

Bol. Acad. peru. leng. 55(55), 2013 
ayuda'. El corrector es, pues, llamado para que ayude a curar, aliviar y cuidar los textos palabra por palabra, letra por letra, cuando estos están dañados por la ignorancia o por la falta de atención. Es una labor difícil que exige, sobre todo, saber hablar y escribir con justeza la lengua en que están compuestas las obras que corrige, y tener cierta cultura general que, por lo menos, lo induzca a consultar bien la bibliografía adecuada. Tiene que tener en cuenta que, en su trabajo, no cabe la mediocridad y no se cumple el dicho español: "Los errores del que cura con la tierra han cobertura", pues no hay tierra que tape ni los errores que no ve ni los que puede introducir por desconocimiento. Cuenta Umberto Eco que en un pasaje de la versión francesa de un libro suyo en italiano sobre estética medieval, el traductor escribió "las cinco plagas de Egipto". Un lector atento y culto observó la expresión y le comunicó a Eco su desconcierto, pues las plagas de Egipto habían sido diez. Eco, que había citado de una fuente original en italiano, la revisó y advirtió que en esta se mencionaban "cinco plagas", pero no "de Egipto". ¿Qué había sucedido? El traductor al francés, sin duda poco avisado, no reparó en que piaghe, en italiano, denota 'plagas', pero también 'llagas', y que, en ese fragmento del libro, Eco se refería a las cinco llagas de Cristo (manos, pies y costado). Al escribir erróneamente "cinco plagas", le agregó — suponemos sin pensar mucho y para demostrar su falsa cultura- "de Egipto” y quedó muy contento con este híbrido. Nos preguntamos: ¿dónde estaba la mente del corrector cuando tuvo ante sus ojos el texto?, pues la distracción no es menor. ¿Con qué autoridad modificó el traductor el contenido de la obra? ¿No confió en la idoneidad del autor, ya que este es —según el semiólogo italiano"la persona menos indicada para descubrir los propios errores"2? Como decía la escritora española Concepción Arenal Ponte (1820-1893), "con la ignorancia armonizan bien los errores”. Este breve ejemplo simboliza la complejidad de la tarea, pero, al mismo tiempo, su dimensión, pues - como dijimos - corregir no solo reside en colocar una tilde o en suprimir una forma verbal mal habida, sino también en conocer el espacio y el tiempo de la cultura, y hasta en ahondar en la cosmovisión de los autores. Por eso, después de realizado el trabajo, cada corrector se ha transformado, es otro; las palabras lo han creado nuevamente.

“El arte de la edición”. La Nación, Buenos Aires, 26 de octubre de 1997. 
¿Qué debe “curar”, entonces, el profesional en los textos? Analizaremos algunos ejemplos:

- la acentuación perdida (Curso de Ingles a distancia para Profesionales de la $\underline{S}_{a l u d}{ }^{3}:$ ¿para qué un curso a distancia si pueden ver las ingles en cuanto paciente los visite?; ¿por qué las mayúsculas en Profesionales y en Salud?);

- las delirantes construcciones laberínticas que causa el desorden de las palabras (Mujeres compulsivas en liquidación ${ }^{4}$ : ¿acaso, por sus impulsos irresistibles, nadie las quiere, y las liquidan? Lo correcto es Mujeres compulsivas en una venta de ropa en liquidación; La mujer malasia va a luchar por una medalla embarazada de ocho meses; Esta deportista de Malasia compitió en tiro con rifle con ocho meses de embarazo ${ }^{5}$. iVaya medalla y vaya rifle! Este siglo XXI nos sorprende. Otros ejemplos: Uniformes de invierno para oficinas ${ }^{6}$ (icuánta formalidad en esa empresa y cuánta consideración al evitar que las oficinas tengan frío!); iTapados para niñas en cuotas! ${ }^{7}$ Y para niñas en efectivo, ¿no hay tapados?);

- los galimatías sintácticos (El caballero que me lo trajo (se refiere a un reloj ferroviario) pertenecía a su abuelo ${ }^{8}$ : ¿era el caballero una posesión del abuelo?);

- la sintaxis extranjerizante (galicismos: ¿Cómo fue que ocurrió?, por ¿Cómo ocurrió?; Fue en este lugar que lo encontraron, por Fue en este lugar

3 First Studio Institute [en línea]. <http://www.laguiadelvalle.com.ar/capacitacion/curso421-ingles-para-medicina-y-profesionales-de-la-salud.htm $>$ [Consulta: 27 de diciembre de 2012].

4 <http://www.videoschistosos.net/mujeres-compulsivas-en-liquidacion-video_fc772b52e. html > [Consulta: 31 de enero de 2013].

5 "Mujeres atletas hacen historia en Londres 2012", hEb discoverymujercom [en línea]. $<$ http://www.discoverymujer.com/salud/ejercicios/mujeres-atletas-hacen-historia-enlondres-2012/> [Consulta: 22 de diciembre de 2012].

6 Clasificados.com [en línea]. <http://pe.clasificados.com/uniformes-de-invierno-paraoficinas-41840 $>$ [Consulta: 26 de enero de 2013].

7 <http://listado.mercadolibre.com.ar/tapados-para-niñas_DisplayType_G> [Consulta: 28 de diciembre de 2012].

8 National Geographic [programa televisivo], 23 de enero de 2013.

Bol. Acad. peru. leng. 55(55), 2013 
donde lo encontraron o En este lugar, lo encontraron. Deben evitarse, pues, las siguientes expresiones galicadas: *es por eso que, *por eso es que, *fue entonces que, *es así que, *abi es que, *fue por ese motivo que y reemplazarse con las correctas es por eso por lo que o por eso; fue entonces cuando o entonces; es así como o así; ahi es donde o ahi; fue por ese motivo por lo que o por eso; anglicismos: Nelson Serrano no pierde la esperanza de ser ballado inocente; Un juez encontró a un niño de 12 años de edad, culpable de asesinato en segundo grado ${ }^{9}$; Este nuevo medicamento es una alternativa al jarabe que le receté el año pasado; Esa medalla es posible de ganar; Estamos regresando el lunes; ¿Hay ningún trabajo tan fácil como el de callar?; ¿Quién te dijo nunca con voz amiga que no abandonaras tus sueños?, por Nelson Serrano no pierde la esperanza de ser declarado inocente; Un juez declaró a un niño de 12 años culpable de asesinato en segundo grado; Este nuevo medicamento es una alternativa del jarabe que le receté el año pasado; ¿Puede ganarse esa medalla?; Regresaremos el lunes; ¿Hay un trabajo más fácil que callar?; ¿Quién te dijo con voz amiga que no abandonaras tus sueños?; italianismos: En base a lo anteriormente expuesto, no podemos votar en favor del informe, por Sobre la base de lo expuesto anteriormente, no podemos votar a favor del informe; No hay más niños en el aula ${ }^{10}$, por Ya no hay niños en el aula);

- la sintaxis sintética (Reformamos su $4^{0}$ de baño: el baño completo no porque cuesta muy caro; en realidad, el texto dice "su cuatro grados de baño");

- la impropiedad en el uso del léxico (Por razones climatéricas, los trenes llegarán con retraso: parece, pues, que algunos trenes hembra ya sufren el climaterio o período de declinación sexual y no la acción del clima; Jornada de difusión de la enfermedad celíaca ${ }^{11}$ : además de las mayúsculas que faltan en las palabras significativas del nombre de la Jornada, sin duda alguna, no difundirán la enfermedad, sino las

9 Notibuzz. El periódico de la web [en línea]. <http://www.notibuzz.com/2013/01/nino-de12-anos-de-edad-es-culpable-de.html $>$ [Consulta: 7 de febrero de 2013].

10 Non ci sono più bambini in classe.

11 El informante, San Nicolás, 31 de enero de 2013 [en línea]. <http://www.diarioelinformante.com.ar/notamaster.php?id $=21427>$ [Consulta: 31 de enero de 2013]. 
características de esta; Se celebra el funeral de uno de los ancianos de Ciempozuelos ${ }^{12}$ : difícilmente pueda festejarse un funeral, salvo que el anciano no fuera muy querido; El más famoso mural de Diego Rivera sufre daños irreversibles ${ }^{13}$ : las cuatro acepciones del verbo sufrir se refieren a personas, por lo tanto, no está bien usado en este contexto; además, resulta inadecuado para el sustantivo daños el adjetivo irreversibles, pues ¿puede un daño volver a un estado anterior?; ¿cuál es el estado anterior de un daño? Los daños pueden subsanarse o no, ser reparables o irreparables; en cambio, la erosión de las rocas, el envejecimiento, la ruptura o rotura de un vaso o de un huevo son procesos irreversibles. Por eso, debió decir En el más famoso mural de Diego Rivera, se observan daños irreparables);

- las comas distraídas, que se olvidan de ocupar su lugar en el texto (Piso exterior con ascensor de 3 dormitorios, salón, cocina, baño, aseo y 2 terrazas $^{14}$ : ¿será un ascensor para huéspedes?); y las pecadoras, que quiebran cuanta estructura gramatical les hace un lugarcito $(E l$ yoga para embarazadas, contribuye a acceder a emociones escondidas en el cuerpo... ${ }^{15}$ : no creemos que contribuya mucho a una lectura fluida esa coma entre sujeto y predicado, que corta la respiración);

- el adjetivo mismo que deviene pronombre sin serlo (Vendo impresoras de etiquetas y cabezales para las mismas ${ }^{16}$, en lugar de para estas);

12 Lainformacion.com [en línea]. <http://videos.lainformacion.com/espana/se-celebra-elfuneral-de-uno-de-los-ancianos-de-ciempozuelos_siqolIWqDqR9q0JEP1tnX2/> [Consulta: 2 de febrero de 2013].

13 "Hemeroteca", ABC.es. Cultura, Madrid, 13 de noviembre de 2007 [en línea]. <http:// www.abc.es/hemeroteca/historico-13-11-2007/abc/Cultura/el-mas-famoso-mural-dediego-rivera-sufre-da\%C3\%B1os-irreversibles_1641338536061.html> [Consulta: 2 de febrero de 2013].

14 "Anuncios por palabras", Morderse la lengua, Instituto Cervantes [en línea]. <http://cvc. cervantes.es/actcult/morderse_lengua/expo/anuncios/anuncios_08.htm $>$ [Consulta: 31 de enero de 2013].

15 Eliana Mariela D’ALESSANDRO, Yoga para embarazadas. Conocimientos generales [en línea]. $<$ http://www.creandotuvida.com/yoga_embarazadas.html> [Consulta: 25 de diciembre de 2012].

16 <http://flores.olx.com.ar/impresoras-de-etiquetas-y-cabezales-para-las-mismas-origenusa-iid-40153337> [Consulta: 3 de enero de 2013]. 
- los innecesarios adjetivos posesivos anglicados, de carácter pleonástico (Apóyese en el suelo, sobre sus manos y rodillas en una superficie no deslizante. Sitúe sus rodillas directamente debajo de sus caderas y sus manos un poco más allá de sus hombros... ${ }^{17}$; iqué ejercicio extraño y qué insistencia al repetir sus!; imaginamos que las manos, las rodillas y las caderas le pertenecen a esa persona);

- los complementos directos pleonásticos que tornan inelegante la redacción, más aún si van acompañados de una coma (Lo nuevo, lo distinto, también lo encontramos en esos compositores, por También encontramos lo nuevo, lo distinto en esos compositores);

- los gerundios entremetidos, que a empujones se arriman a cuanta palabra les da cabida para no perder protagonismo (Decenas de hormigas negras rozaban sus pies, empezando a subirse por sus piernas (corrección: Decenas de hormigas negras rozaban los pies y empezaban a subirse por las piernas); A raíz del accidente, el motociclista sufrió lesiones en miembros inferiores, siendo trasladado al hospital local presentando traumatismo de rodilla izquierda con fractura expuesta ${ }^{18}$ : así escrito, parece que el hospital local también estaba averiado (corrección: A raíz del accidente, el motociclista sufrió lesiones en miembros inferiores: traumatismo de rodilla izquierda y fractura expuesta, y fue trasladado al hospital local);

- el pretérito imperfecto del modo subjuntivo que quiere ocupar ilegítimamente el lugar del pretérito perfecto simple o de manera arcaica el del pretérito pluscuamperfecto del modo indicativo (Comenzó a emitir en modo de prueba el 10 de diciembre de 1995, luego que se adjudicara la onda a Elvio Erazu quien fundara la emisora ${ }^{19}$; corrección:

17 Yoga inbound [en línea]. <http://www.yogainbound.org/hatha_yoga/asanas/adho_ mukha.php $>$ [Consulta: 3 de enero de 2013].

18 "Motociclista lesionado tras accidente en Ruta 12", policialesenlinea.com, Misiones (Argentina), 21 de diciembre de 2012 [en línea]. <http://policialesenlinea.com/index. php?option $=$ com_content $\&$ view $=$ article $\& i d=3807$ : motociclista-lesionado-trasaccidente-en-ruta-12-\&catid $=3$ :provinciales $\&$ Itemid $=3>$ [Consulta: 24 de diciembre de 2012].

19 <http://www.fmnicoperez.com/historia.html> [Consulta: 24 de diciembre de 2012]. 
Comenzó a emitir a modo de prueba el 10 de diciembre de 1995, luego que se adjudicó la onda a Elvio Erazu, quien había fundado la emisora);

- la correlación verbal alterada (El hombre había ocultado la droga en el fondo del predio, y si bien en un primer momento consiguió que no la descubran. al final resultó "delatado" por su propia oveja $a^{20}$ a la forma verbal babia ocultado corresponde la forma verbal que no la descubrieran; Publicaron datos del actor antes que ocurra el robo ${ }^{21}$, en lugar de ... antes que ocurriera el robo);

- las preposiciones que denominamos "turistas", pues nos recuerdan construcciones de otras lenguas (¿Cuáles son las disposiciones a adoptar para prevenir accidentes a bordo de los buques? [galicismo: en español, por adoptar; para adoptar]; La reunión resultó en un fracaso [anglicismo: en español, ... resultó un fracaso]; Esperé por ella dos horas [anglicismo: en español, La esperé dos horas]; Viajó a Piura por dos semanas [en español: Viajó a Piura dos semanas]; Se fueron por tres meses de gira [en español: Se fueron tres meses de gira]; Estudiaban el trastorno del comportamiento relacionado al sueño [en español: ... relacionado con el sueño]; La Policía Nacional localizó el vehículo buscado en relación al asesinato de un mecánico el pasado martes... ${ }^{22}$ [en español: ... en relación con el asesinato... o ... con relación al asesinato...]; Las trabajadoras despedidas han recibido una cantidad de dinero mayor a sus pretensiones iniciales [en español: ... mayor que...]; Fue encontrado en la tarde del martes por la patrulla de rescate en la zona del glaciar de los Polacos ${ }^{23}$ [anglicismos]; en español: ... a la tarde... o ... por la tarde...); las preposiciones ambiciosas, que se cuelan en el texto para no faltar

20 “Ocultó drogas en su casa, pero lo 'delató' una oveja”, Diario Uno.com [en línea]. <http:// www.diariouno.com.ar/mundo-insolito/Oculto-drogas-en-su-casa-pero-lo-delato-unaoveja-20121012-0016.html> [Consulta: 23 de diciembre de 2012].

21 Intrusos, programa televisivo, Buenos Aires, 30 de enero de 2013.

22 "Hallan camioneta relacionada a homicidio de mecánico", abc color, Paraguay, 2 de enero de 2013 [en línea]. < http://www.abc.com.py/nacionales/hallan-camioneta-relacionada-ahomicidio-de-mecanico-496806.html> [Consulta: 3 de enero de 2013].

23 Diario Panorama, Santiago del Estero (argentina), 3 de enero de 2013 [en línea]. < http:// www.diariopanorama.com/diario/> [Consulta: 3 de enero de 2013].

Bol. Acad. peru. leng. 55(55), 2013 
y siempre están de más (¿Creen de que somos máquinas? [dequeísmo]; La empresa atraviesa por una crisis económica; Los expertos alertan de que el deshielo del Ártico amenaza la población de osos polares ${ }^{24}$; Según la edad del paciente y del tipo de fractura, el yeso se deja colocado durante solo 4 semanas o durante 10 semanas $^{25}$ : la repetición de la contracción del nos permite interpretar que el tipo de fractura tiene edad, y de esta dependerá el tiempo en que deberá padecer el yeso. Si la fractura es reciente, creemos que será una "beba" de algunas horas); las preposiciones entrometidas, que ocupan el lugar de otras preposiciones (Los políticos de un partido discrepaban con los de otro en temas económicos: si unos discrepaban con otros, significa que los políticos de ambos partidos no discrepaban entre sí, sino de un tercero, por lo tanto, esos políticos estaban de acuerdo y en contra de un tercer grupo de políticos; pero si no se ha querido decir eso, debió usarse la preposición de; Chocó, escapó en contramano y causó una tragedia: la locución adverbial es a contramano, pero los diccionarios han dejado de consultarse); las preposiciones económicas, pues el que redacta usa una para dos o más palabras sin advertir si cada una de estas tiene el mismo régimen preposicional (Asistió y disfrutó de la reunión en lugar de Asistió a la reunión y disfrutó de esta); las preposiciones tímidas, que, generalmente, no aparecen y generan queísmo (Se dio cuenta que la vida no era eso; Estaban seguros que ganaban); las preposiciones osadas, que se coordinan y le quitan elegancia a la redacción (Imágenes de tallarines sin y con salsa; Ha entrado en y salido de la quiebra ${ }^{26}$ );

- las letras descarriadas (en la vidriera de una papelería, escribieron con envidiable voluntad gastronómica: Agenda cocida ${ }^{27}$, es decir, ni cruda ni asada; El sacerdote parecía embelezado con sus propias frases $y$

24 "Naturaleza viva" [en línea]. <http://diariode3.com/los-expertos-alertan-de-que-eldeshielo-del-artico-amenaza-la-poblacion-de-osos-polares/> [Consulta: 22 de diciembre de 2012].

25 Cirugías y procedimientos: yesos y férulas [en línea] <http://kidshealth.org/parent/emmi kids/casts_splints_esp.html > [Consulta: 5 de diciembre de 2012].

26 Auto $M K \overline{[}$ [en línea]. http://spanish.autonp.com/thread-132904-1-1.html [Consulta: 25 de enero de 2013].

27 San Rafael (Mendoza), enero de 2013. 
así lo transmitía ${ }^{28}$ : como *embelezado con $z$ no comunica ningún significado, no sabemos qué le pasaba al sacerdote ni qué deseaba transmitir; embelesar es 'cautivar los sentidos'; Con paños de agua fría intentaba palear la transpiración ${ }^{29}$ : *palear significa 'trabajar con pala'; si usó los paños a modo de pala, cómo le quedaría la cara; $E l$ sol del 28 de enero era abrazador ${ }^{30}$ : esta última palabra, escrita con $z$ en lugar de con $s$, denota 'que abraza, que da abrazos'; ni una personificación toleraría el abrazo del sol; Las depositó (las pavas) en la mesa, al lado de las tasas de porcelana francesa ${ }^{31}$; ise referirá a sofisticadas tasas de desempleo, de inflación o de natalidad?);

- el corrector debe conocer las clases de palabras, pues, de lo contrario, dejará como correctas oraciones como la siguiente: No quería ni pensar en que eran medio hermanas (debe usarse el adjetivo, no el adverbio: medias hermanas);

- debe suprimir las rimas entre vocablos y "leer con los oídos en los ojos" 32 esa prosa que no se resigna a ser prosa, porque tiene veleidades de poesía (Es un examen sistemático e independiente para determinar si las actividades de calidad y los resultados relacionados cumplen con los acuerdos planificados y si estos acuerdos están efectivamente implementados y son adecuados para alcanzar los objetivos ${ }^{33}$ );

- las repeticiones que fatigan el texto cuando son superfluas (.. planificación de calidad, control de calidad, aseguramiento de calidad y mejoramiento de la calidad dentro del sistema de calidad, por ... planificación, control, aseguramiento y mejoramiento de la calidad dentro del sistema de esta);

28 Florencia CANALE, Pasión y traición. Los amores secretos de Remedios de Escalada de San Martín, 5. a edición, Buenos Aires, Planeta, 2012, p. 111.

29 Ibídem, p. 156

30 Ibídem, p. 190.

31 Ibidem, p. 51.

32 Juan Ramón JIMÉNEZ. Ideolojía. Barcelona, Anthropos, 1990, p. 719.

33 Guía técnica de buenas prácticas de manufactura (GMP) para la industria de productos cosméticos [en línea]. <http://www.ispch.cl/sites/default/files/u24/Guia_tecnica_GMP_ Cosmetico_0.pdf $>$ [Consulta: 24 de diciembre de 2012]. 
- además, debe perseguir las indiscretas erratas que nunca faltan (el titular de un diario español dice lo siguiente dos días antes de terminar el año 2012: Alta presencia de esquiadores para acabar un irregular 2013 $3^{34}$. iQué poder para anticipar a fines de 2012 todo el año siguiente! Y, sobre todo, para acabarlo, verbo que crea cierta ambigüedad, ya que, en América, denota también 'matar'. Leído así, parece que los esquiadores se hubieran conjurado para matar un año que ni siquiera había comenzado); El japonés Kengiro Shinozuka, muy grave tras volar por encima de una duda ${ }^{35}$ (seguramente, no quiso resolverla; en realidad no era una $d u d a$, sino una duna la que le provocó el accidente al automovilista, ganador del Dakar en 1997. El ejemplo es oportuno, pues bien puede compararse una duda con una duna o 'colina de arena movediza que en los desiertos y en las playas forma y empuja el viento');

- las tildes que sobran (¿Quién te quiere a tí? ?). Corrobora esos graves deslices esta noticia: El pueblo de Fuentes de Magaña ha construído la mayor maqueta del mundo para reactivar el turismo pelontológico en la $z o n a^{36}$. Aprovechamos el ejemplo para aclarar que el periodista quiso decir paleontológico, pero no tuvo suerte y, en lugar de referirse a los turistas aficionados al 'estudio de los seres antiguos', aludió al estudio de los pelones, es decir, de los 'seres que no tienen pelo o que tienen muy poco', por lo tanto, a los turistas calvos o casi calvos. iUn turismo, realmente, elegido!

- el anantapódoton, vocablo adusto, de apariencia prehistórica, pero inofensivo que denota 'privado de correspondencia simétrica', pues se omite en el texto un sintagma correlativo a otro (En primer lugar

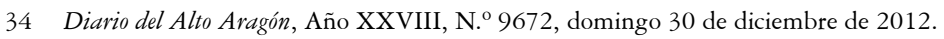

35 Morderse la lengua, Instituto Cervantes [en línea]. http://cvc.cervantes.es/actcult/ morderse_lengua/anuncios.htm [Consulta: 31 de enero de 2013].

36 "Pasen y vean en Fuentes de Magaña el dinosaurio más grande del mundo entero", Diario El Mundo.es, Madrid, 18 de noviembre de 2012 [en línea]. <http://www.elmundo.es/ elmundo/2012/11/17/castillayleon/1353172178.html> [Consulta: 18 de noviembre de 2012]. 
sacaremos los huevos de la nevera por lo menos una hora antes, para que estén a temperatura ambiente (muy importante) y se batan bien. Ponemos en un bol grande los huevos y los batimos a mano o mejor con una batidora de varillas ${ }^{37}$ ); si se escribió en primer lugar, debe agregarse luego en segundo lugar.

Realmente, el trabajo del corrector es múltiple y no se circunscribe solo a estos aspectos, ya que también debe saber leer el texto para comprenderlo; evaluar la coherencia y la cohesión del contenido, y, por supuesto, verificar la precisión de los datos que aparecen en él (nombres propios, nombres geográficos, nombres históricos, títulos de obras, fechas, marcas registradas, etc.). Ni Napoleón nació en 1679 (por 1769); ni el río Azul corre en el norte de la Argentina; ni Calderón de la Barca escribió Fuenteovejuna; ni el vago es un músculo de nuestro cuerpo, sino un nervio; ni la marca Ford se escribe con letra redonda, sino con cursiva, pues así fue inscripta. Por lo tanto, la tarea es ardua, y no siempre las editoriales tienen una persona preparada para corroborar esta clase de conceptos.

Como lo habrán advertido, todos los textos son valiosos para un corrector. Una sola oración, un folleto publicitario serán tan importantes como un diccionario, una novela completa, una obra científica o una receta de cocina. Ante todos, sea cual fuere la especialidad a la que pertenezcan, deberá enfrentarse con el mismo rigor, con la misma autoridad moral, con el mismo conocimiento. Por ejemplo, llega a sus manos un libro sobre jardinería y encuentra la siguiente oración:

Las terrazas con situaciones muy soleadas, requerirán plantas con una naturaleza que toleren el sol sin problema ${ }^{38}$.

Aunque lea la oración tres veces, el corrector no sabrá cuáles son las situaciones de las terrazas ni las plantas con una naturaleza. Además,

37 "Magdalenas... de la abuela" [en línea]. < http://www.elrincondemarimel.com/micocina/ magdalenas-de-la-abuela.htm $>$ [Consulta: 4 de febrero de 2013].

38 "Jardineras de verano", Plantas y flores [en línea]. <http://plantayflor.blogspot.com. ar/2010/06/jardineras-de-verano.html > [Consulta: 8 de noviembre de 2012].

Bol. Acad. peru. leng. 55(55), 2013 
estas deben tolerar el sol sin problema. ¿Qué problema puede hacerse una planta? o, leído de otra manera, ¿qué problema puede tener el sol? Estos sintagmas deben ser barridos como la hojarasca, pues no le agregan nada a la oración; solo ocupan lugar. También advertirá la presencia de una coma que quiebra la unidad que se establece entre el sujeto y el predicado. El texto "curado" queda de esta manera: Las terrazas muy soleadas requerirán plantas que toleren el sol.

¿Hay correctores en el medio televisivo? No los hay. Por eso debemos padecer enunciados como los siguientes: Peligro de audición en jóvenes $^{39}$. iBienvenido sea ese peligro si pueden oír bien! El mensaje, en realidad, amenaza lo contrario. Se refiere a la hipoacusia — 'disminución o pérdida de la audición'- que puede causar el uso de auriculares para escuchar música. Otro ejemplo: Ellos son los que perdieron la muerte en el accidente de $\operatorname{tren}^{40}$. Si la perdieron, la encontraron porque, lamentablemente, habían muerto casi todos los pasajeros.

¿Hay correctores en la prensa escrita y en la digital? A veces, parece que no, pues escriben titulares ambiguos: $U n$ avión ameriza en el río Hudson sin ningún muerto ${ }^{41}$. ¿Tenía que llegar con pasajeros muertos? Conocemos el hecho y sabemos que no fue así, pero lo escrito escrito está, y ese es el mensaje que se ha comunicado. La exigencia de economía verbal distorsiona el significado. Veamos otro ejemplo: Ante emergencias con riesgo de vida llamá al 107. ¿Cómo pueden las emergencias tener riesgo de vida? ¿Qué es el riesgo de vida? Querrá decir "riesgo de muerte" o "riesgo de perder la vida". La palabra emergencias denota 'situación de peligro o desastre que requiere una acción inmediata'; 'accidente', por lo tanto, lo que se agregue carece de valor.

¿Hay correctores en el ámbito publicitario? Si los hay, deben reflexionar mucho más sobre los textos que tienen ante sus ojos. Los ejemplos son infinitos. Y este supera nuestra imaginación: Venta de verano,

39 "Noticiario", Todo Noticias, Buenos Aires, 4 de diciembre de 2012.

40 Noticiario, Buenos Aires, 23 de febrero de 2012.

$41<$ http://bitacoras.com/anotaciones/un-avion-ameriza-en-el-rio-hudson-sin-ningunmuerto/4550191> [Consulta: 4 de diciembre de 2012]. 
mujer de paja contra el sombrero para el sol (circunferencia de $56-58 \mathrm{~cm}$ ) a precio al por mayor ${ }^{42}$. ¿Se vende una mujer de paja? ¿Una mujer de paja está en contra de un sombrero para el sol? ¿Qué habrá hecho el sombrero? ¿Se quedará el sol sin él para protegerse de sí mismo? ¿Dónde se ha escondido la sintaxis del autor de este texto y la del corrector para que entendamos el mensaje?

En fin, considerarse corrector no solo significa enmendar enunciados u oraciones que tienen errores gráficos o morfosintácticos, sino también cuidar la semántica del texto. De acuerdo con lo que dijimos - y vale repetirlo_-, primero el profesional debe saber escribir muy bien para reconocer lo que está bien y mal escrito, pues, si lo desconoce, puede cometer errores graves o incurrir en hipercorrecciones.

El corrector empieza día a día nuevamente, pues cada texto es el comienzo de una aventura; cada texto aparece, a veces, como un laberinto profundo, oscuro, en el que las dudas despliegan sus sombras detrás de cada coma, junto a una preposición, entre las sílabas de vocablos que tuercen su camino semántico. Sí, cada texto es un laberinto desafiante, cuya salida no está en ninguna parte, pero tiene que aparecer; debe encontrarse para ver otra vez la luz, y que el texto respire nuevos aires. En algunas ocasiones, el corrector sucumbe en medio de un huracán de errores y de dudas que lo atosigan, y no sabe cómo salvarse de estos, pero debe seguir sin impaciencia, no rendirse nunca. Expondremos algunos de estos momentos de alta tensión que ponen trabas a la continuidad serena del trabajo:

\section{Ejemplo 1}

Al 31 de diciembre de 2011, se encontraban en ejecución 8 obras de expansión que involucran a 8 provincias del País y que implican la instalación de más de $430 \mathrm{~km}$ de gasoductos troncales y $750.000 \mathrm{~m}$ de redes de distribución, y el beneficio para más de 160.000 usuarios.

42 Lightinthebox.com [en línea]. <http://www.lightinthebox.com/es/verano-mujer-de-pajacontra-el-sombrero-para-el-sol-circunferencia-de-56-58cm_p376363.html> [Consulta: 23 de diciembre de 2012].

Bol. Acad. peru. leng. 55(55), 2013 
Ante este texto, un corrector que no ha recibido la formación necesaria puede formularse varias preguntas:

- ¿Puede decirse al 31 de diciembre? El mes, ¿se escribe con minúscula?

- ¿De 2011 o del 2011?

- La coma que aparece después de 2011, ces correcta?

- Si dice se encontraban en ejecución, en pretérito imperfecto de indicativo, ¿es válida la forma verbal involucran, del presente del modo indicativo?

- ¿Involucran a 8 provincias o debe suprimirse la preposición $a$ ?

- Respecto del número 8 , ¿se deja la cifra o se la convierte en palabra?

- Provincias, ¿se escribe con mayúscula o con minúscula?

- La palabra País, ¿puede usarse con mayúscula cuando se refiere a un país concreto?

- El símbolo de kilómetros, clleva punto o no; va con mayúscula o con minúscula? En lugar del símbolo, ¿puede escribirse kilómetros junto al número 430 ?

- Las cifras 750.000 y 160.000 , ¿están bien escritas con punto o no?; ¿deben escribirse con palabras? ${ }^{43}$

- ¿Se repite la preposición de en el sintagma de $430 \mathrm{~km}$ de gasoductos troncales y $750.000 \mathrm{~m}$ de redes de distribución, o no?

Envuelto en este auténtico dudario, tal vez, no advierta la jungla de rimas que entorpecen la escritura y la tornan monótona: ejecución, expansión, instalación, distribución. Para evitarlas, deberá recurrir a los sinónimos o cambiar la redacción del texto sin alterar su significado:

Al 31 de diciembre de 2011, estaban realizándose 8 obras de expansión que involucraban a 8 provincias del país. Se proponía instalar más de $430 \mathrm{~km}$ de gasoductos troncales y de $750.000 \mathrm{~m}$ de redes de distribución, y beneficiar a más de 160.000 usuarios.

43 El uso del punto en cifras complejas, es decir, de cinco o más dígitos, depende de la norma de cada país. 
Ejemplo 2

Luego de presenciar el conflicto verbal, los hijos de la mujer de 14 y 16 años decidieron golpear ferozmente al sujeto... ${ }^{44}$.

¿Será la primera mujer que padece dos edades? La ausencia de comas ha creado este galimatías:

Luego de presenciar el conflicto verbal, los hijos de la mujer, de 14 y 16 años, decidieron golpear ferozmente al sujeto...

\section{Ejemplo 3}

La Policía descartó el lunes la posibilidad de que un intruso haya cometido el ataque o de que hubiera un sospechoso en fuga, pero Nichols dijo luego que los investigadores no habían determinado con exactitud lo que ocurrió ni cuándo en la modesta casa con tres recámaras ${ }^{45}$.

En este texto no enmendado por el corrector o corregido con cierta irresponsabilidad, el pretérito perfecto simple del modo indicativo descartó no puede correlacionarse con el pretérito perfecto de subjuntivo haya cometido, sino con el pretérito pluscuamperfecto de ese modo (bubiera cometido), forma verbal que el autor usa después. Si este dice que los investigadores no habian determinado, la forma verbal que sigue no debe ser *ocurrió, sino había ocurrido, que denota un pasado terminado y anterior al acto de decir de Nichols. La oración correcta es la siguiente: La Policía descartó el lunes la posibilidad de que un intruso bubiera cometido el ataque o de que bubiera un sospechoso en fuga, pero Nichols dijo luego que los investigadores no habian determinado con exactitud lo que había ocurrido ni cuándo en la modesta casa de tres recámaras.

44 "Matan a hombre que discutió con su mamá", diario Crónica, Buenos Aires, 31 de mayo de 2012 [en línea]. <http://www.cronica.com.ar/seccion/policiales.html> [Consulta: 1 de junio de 2012].

45 "Familia hispana agredida en Las Vegas; niña y madre muertas", Aol Noticias [en línea]. $<$ http://noticias.aollatino.com/2012/04/20/familia-hispana-agredida-en-las-vegas-ninay-madre-muertas/ $>$ [Consulta: 1 de junio de 2012].

Bol. Acad. peru. leng. 55(55), 2013 


\section{Ejemplo 4}

Wiggins abandonó el lugar del incidente en camilla, incapaz de caminar por su propio pie $\mathrm{p}^{46}$.

Espeluzna el sintagma por su propio pie, anglicismo exacerbado por el adjetivo propio (bis own foot). Ni el adjetivo su ni el adjetivo propio son necesarios, pues sabemos que el hombre camina con los pies que tiene, ¿o nació con uno, y el otro es prestado o alquilado? La oración correcta es la siguiente: Incapaz de caminar, Wiggins abandonó el lugar del incidente en camilla.

\section{Ejemplo 5}

Según los expertos, el 80 por ciento de los dolores lumbares agudos evolucionan favorablemente con independencia del tratamiento ${ }^{47}$.

Si los dolores evolucionan favorablemente, el paciente que los padece no los aguantará, le resultarán insoportables, más aún con independencia del tratamiento. Esta clase de oraciones se repite de continuo en la Internet y en los libros sobre temas médicos. Una prima hermana de ella es Entérate de los mejores consejos para mejorar la tos y otros síntomas del catarro infantil... ${ }^{48}$ iSin comentarios! Basta recordar que mejorar denota 'pasar a un estado mejor'. Si la tos pasa a un estado mejor, ipobres niños!

Es triste reconocerlo, pero algunos errores provocan risa, mientras que la complacencia en lo correcto pocas veces nos hace sonreír.

46 "Wiggins, hospitalizado tras ser atropellado cuando iba en bici", El Mundo.es, Madrid, 8 de noviembre de 2012 [en línea]. <http://www.elmundo.es/elmundodeporte/2012/11/07/ ciclismo/1352327263.html > [Consulta: 8 de noviembre de 2012].

47 "Expertos españoles muestran la eficacia de la técnica neurorreflejoterápica en los dolores lumbares crónicos", El Médico Interactivo. Diario electrónico de la sanidad [en línea]. <http:// www.elmedicointeractivo.com/ap1/emiold/noticias/2000/07/28/alcierre1.htm > [Consulta: 7 de febrero de 2013].

48 "Consejos para la tos y el catarro infantil" [en línea]. <http://www.jarabeinfantil.com/ consejos-tos-y-catarro-infantil/> [Consulta: 7 de febrero de 2013]. 
Entonces, ante los apuros que generan los textos, no es válido creer que lo menos importante es saber, sino tener a mano el número de teléfono o la dirección electrónica del colega que conoce las normas. El que cree eso no es un corrector, sino un parásito de otros correctores, un siempre jamás para quien el fin — ganar dinero- justifica los medios —que otros le hagan el trabajo—. Un poema de Octavio Paz habla del "lenguaje deshabitado" ${ }^{49}$, expresión que se ajusta al pseudocorrector que vive de él desnudo, vacío, sin él. Esta persona no ve más allá; no advierte que la escritura total que tiene entre sus manos y ante sus ojos es un cuerpo valioso que requiere una detenida observación, es decir, una caricia benefactora y no una metamorfosis que puede desmoronar el mensaje.

El verdadero corrector no puede presentir la lengua; debe vivirla desde adentro, desde su misma raíz, desde el deseo, desde el goce. Por eso, se insiste en que corregir no significa reescribir cada oración del texto. Esta es la tarea cómoda del que desconoce las reglas y del que cree que no necesita estudiarlas. Corregir es un acto de amor profundo, generoso, no de degüello por incultura lingüística.

Es, pues, obligatorio dedicarles mucho tiempo al estudio y a la práctica profesional, a un entrenamiento diario que conserve la salud de lo que sabemos o que nos someta a buenos tratamientos para corregir nuestros olvidos o para enriquecer con actualizaciones la integridad de nuestros trabajos.

La corrección es poesía en la medida en que la asumamos como un arte pleno ligado a nuestra espiritualidad. No podremos trabajar si no sentimos en nuestro interior el temblor vivo de las palabras. Por eso, corregir significa también transportarse desde las orillas de nuestra realidad cotidiana hasta otra dimensión: la del más allá de los textos. El corrector de excelencia reconoce, pues, que no puede confinarse en la ignorancia a la que aspira ardorosamente buena parte de la sociedad del

49 “Blanco", Blanco (1966), obra poética (1935-1988), Barcelona, Seix Barral, 1998, p. 486.

Bol. Acad. peru. leng. 55(55), 2013 
siglo XXI con su desinterés por la cultura ni naufragar en las aguas de la resignación o del conformismo.

Sabemos que algunas editoriales banalizan la tarea del corrector y, para estar a la altura de los tiempos, le piden que solo sobrevuele los textos, que no se detenga en detalles, es decir - y para emplear las palabras de moda-, que haga una corrección divertida, rápida, superficial, en la que, sin duda, las reglas casi no tienen cabida. En resumen, que la corrección tenga la apariencia de una corrección. Esta falta de ética, que invade tantos ámbitos pseudoprofesionales, debe combatirse, pues ahoga el respeto a la verdad y el culto al esfuerzo. Sin verdad, sin pasión y sin esfuerzo no existe profesión alguna, sino un teatro de monigotes que se obstinan en inmortalizar la nada. Corregir un texto no es un entretenimiento, sino un trabajo de inmensa responsabilidad que requiere disciplina, autoexigencia, atención, orden e insaciable sed de estudio, pues, en definitiva, se busca que el texto alcance el arte de la armonía o, como escribió el poeta Juan Ramón Jiménez, “ordenar la sorpresa" ${ }^{\circ}$.

Es necesario, entonces, que, en cada país de habla española, exista un instituto dedicado exclusivamente a la formación de correctores, que, como otros profesionales, reciban el diploma que acredite esa formación especial, seria, profunda, rigurosa, ya que saber corregir también implica poseer una metodología de trabajo que, aunque se crea lo contrario, el oficio no da. Los alentamos, pues, con gran entusiasmo para que funden la carrera de corrector en el Perú.

Según Aristóteles, "los grandes conocimientos engendran las grandes dudas". Más se instruye el corrector, más duda, pero también es cierto que, si está comprometido con su trabajo, cuando más duda, no le alcanzan los libros para instruirse. Si esto sucede, ha hallado el buen camino, puesto que está seguro de que la consigna de su vocación es siempre volver a empezar, tener constante sed de aprender, apasionarse cada día más del mismo entusiasmo que lo lleva a amar las palabras, y no

Ideolojía (1897-1957). Metamorfosis, IV, Barcelona, Anthropos, 1990, p. 385. 
detenerse nunca para seguir sirviendo humildemente a los demás, pues en esto también reside el valor de esta profesión.

\section{Correspondencia:}

Alicia María Zorrilla

Miembro de la Academia Argentina de Letras

Correo electrónico: aliciazorrilla@arnet.com.ar 